CASE REPORTS

\title{
CONG ENITAL ARTERIOVENOUS FISTULA OF THE INTERNAL MAMMARY VESSELS
}

BY

\author{
B. G. WELLS AND R. L. HURT \\ From St. Bartholomew's Hospital
}

Elkin and Warren (1947) have described traumatic arteriovenous fistulæ in practically every named blood vessel of the body with the exception of the aorta. Congenital arteriovenous fistulæ are much less common. Thus Callander (1920) found only three congenital cases in a series of 447 arteriovenous fistulæ. The usual location of congenital arteriovenous fistulæ in the systemic circulation is in the extremities, or head and neck. Pemberton and Saint (1928) believed that the trunk was rarely if ever affected. Adams (1951) described congenital arteriovenous fistulæ of the pancreas, spleen, and kidney, but none in the thorax. Johnson (1954), and Peräsalo and Kyllönen (1954), have described congenital arteriovenous fistulæ of the subclavian vessels simulating patent ductus arteriosus. Maier and Stout (1950) report a case of congenital arteriovenous fistula of the internal mammary vessels with a hæmangioma of the pectoralis major muscle. Other cases of hæmangioma and arteriovenous fistula of the chest wall have been reported by Takaro and Claggett (1951).

\section{Case History}

The patient, a woman aged 34, had suffered from asthma for many years and in 1942 had been admitted to St. Bartholomew's Hospital under the care of the late Dr. A. E. Gow for investigation of this. No cardiac abnormality was noted at this time. In 1948 she was again admitted to hospital, and for the first time a præcordial murmur resembling that of patent ductus arteriosus was heard: surgical treatment was not advised. In 1954 she began to complain increasingly of dyspnœa on exertion, and because of this an operation to close the presumed ductus was thought advisable. In retrospect, however, it would seem that her dyspnœa was due to her asthma rather than her cardiovascular lesion.

Clinical examination showed there to be a thrill palpable over the second left interspace, and a continuous high-pitched murmur was audible over the same area. The phonocardiogram showed that the vibrations were higher in frequency and more constant in intensity than is usual in patent ductus (Fig. 1). There was no cyanosis or clubbing of the fingers. There was no enlargement of the subcutaneous veins on the front of her chest. The blood pressure was 130/70. The blood count was normal. The chest radiograph showed a heart of normal size and shape, and the lung fields appeared normal. The electrocardiogram was normal.

Because no abnormality had been noted in 1942 it was thought that the diagnosis of patent ductus arteriosus should be confirmed by cardiac catheterization. Although the catheter could not be passed through a patent ductus the oxygen content of the blood in the left pulmonary artery exceeded by 1.88 vols. per $100 \mathrm{ml}$. that of the right ventricle, and by $1.67 \mathrm{vols}$. that of three samples from the main pulmonary artery. This was considered sufficient confirmation of the clinical diagnosis.

At operation on 10/3/55 (R.L.H.) the expected thrill over the pulmonary artery could not be felt, and a dissection of the interval between the pulmonary artery and the aorta showed a normally obliterated ductus arteriosus. It was then noticed that the internal mammary vessels were enlarged and tortuous in their course from the superior mediastinum to the second intercostal space, at which point there was an arterio-venous fistula. A thrill could be palpated over this fistula, and it was abolished by compression of the internal mammary artery proximally. A phonocardiogram and electrocardiogram were taken at the time of operation whilst the internal mammary artery was compressed proximal to the fistula. The vibrations on the phonocardiogram were similar to those previously recorded from the chest wall, showing a frequency of 270 cycles per second. They were completely stopped by compression of the internal 


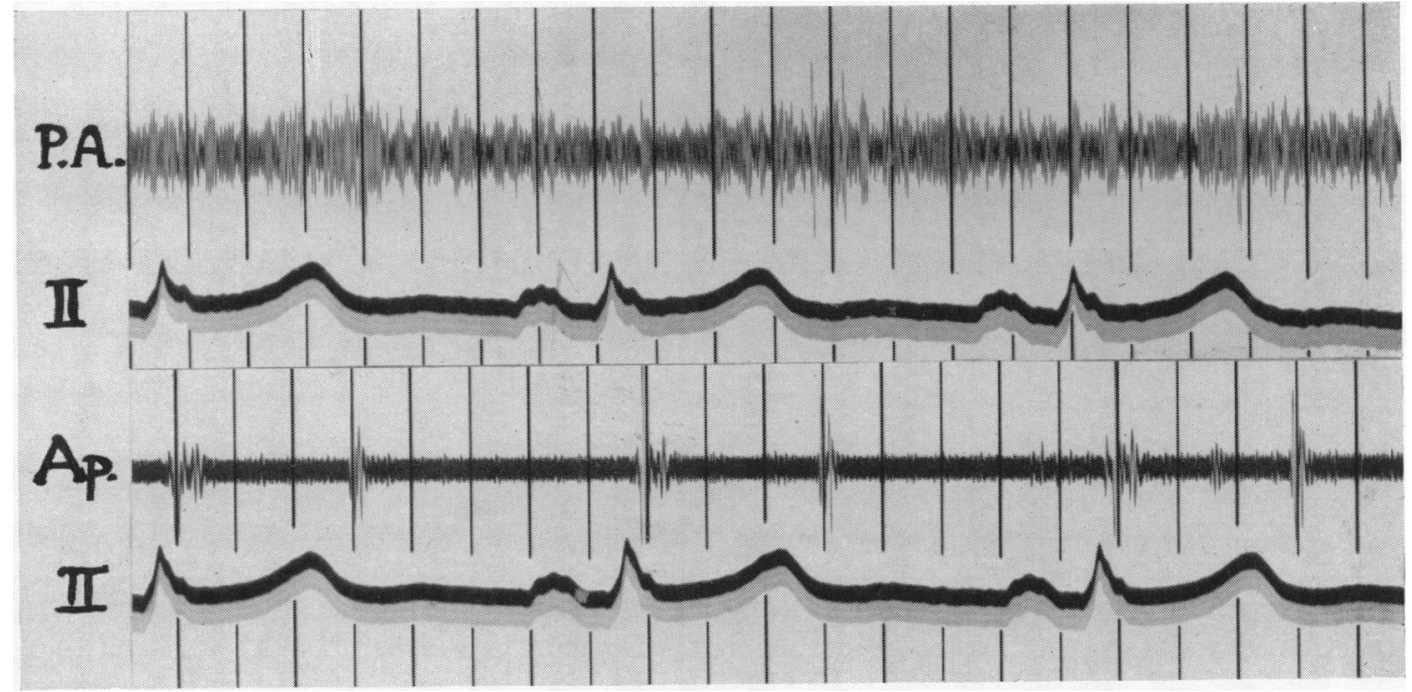

FIG. 1.-Logarithmic (high frequency) phonocardiograms of the continuous murmur in the pulmonary area (P.A.), and of the heart sounds at the apex (Ap.). The reference tracing (II) is Lead II of the cardiogram, and the time lines $\mathbf{0} \cdot 1 \mathrm{sec}$. The frequency of the vibrations $(270 \mathrm{cycles} / \mathrm{sec})$ is higher, and their intensity is more uniform, than is usual is patent ductus arteriosus.

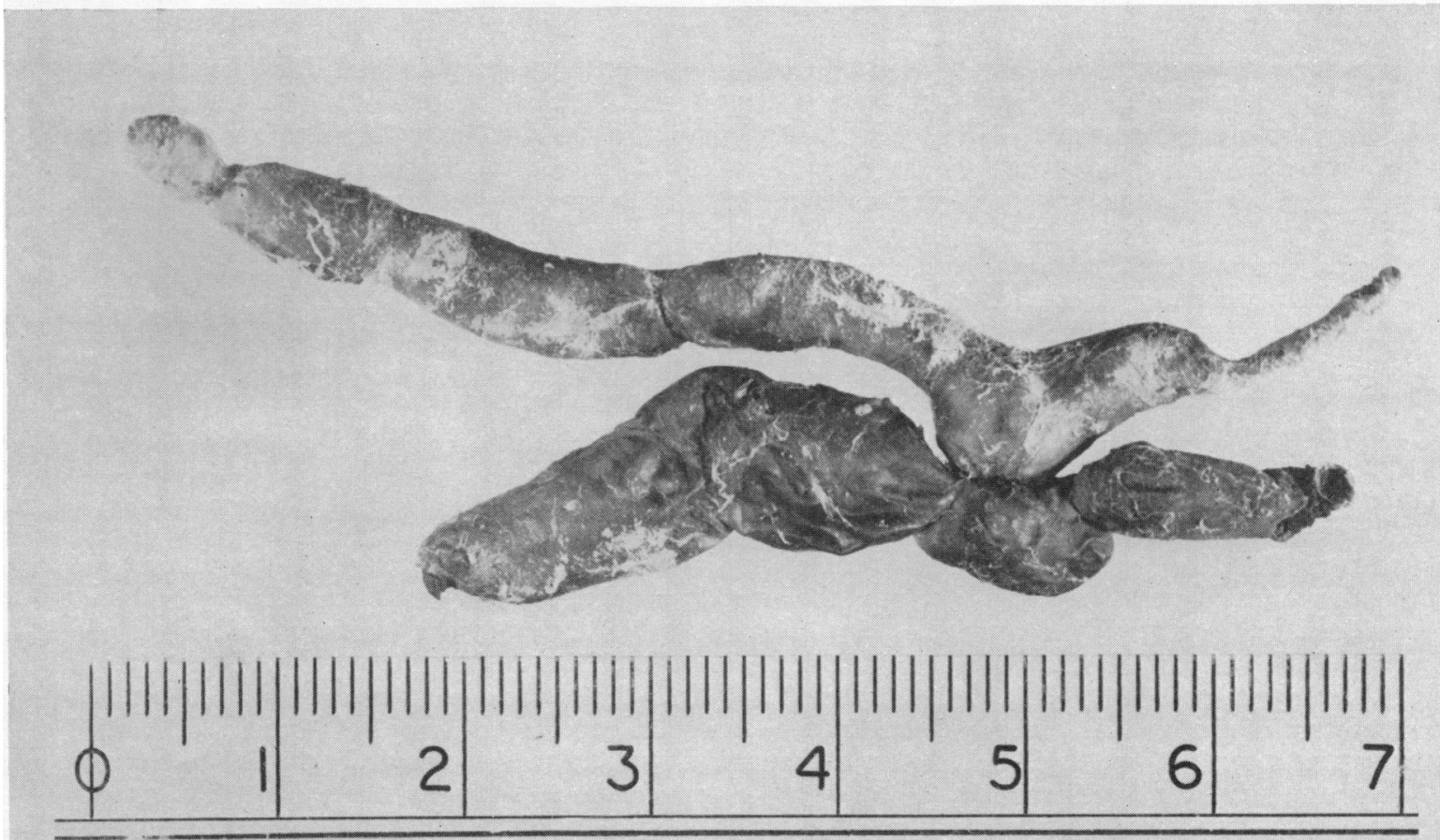

Fig. 2.-The internal mammary vessels with the arteriovenous fistula after excision. 
mammary artery proximal to the fistula, while the electrocardiogram showed some slowing of the heart rate each time this manœuvre was performed.

The internal mammary vessels entering and leaving the fistula were ligated, and the aneurysm was excised. The appearance of the specimen is shown in Fig. 2. The patient's convalescence was uneventful.

\section{Discussion}

The character of the murmur was not typical of patent ductus arteriosus. The murmur had the characters of the murmur of systemic arteriovenous fistula described by Edwards and Levine (1952). However, there was no history of trauma, and no pulsation was palpable as in the case of Maier and Stout (1950).

The absence of cyanosis and clubbing, and the normal lung shadows on the X-ray film suggested that the case was not one of pulmonary arteriovenous fistula. Moreover, the acyanotic case of pulmonary arteriovenous fistula described by Salvesen and Marstander (1951) had no murmur.

The possibility of a coronary arteriovenous fistula was considered, but the cases described by Halpert (1929), Biorck and Crafoord (1947) and Paul et al. (1949) indicate that the diagnosis is difficult without thoracotomy. Wood (1950) states that the oxygen content in samples from the coronary sinus should be unusually high.

The murmur of rupture of a sinus of Valsalva into one of the cavities of the heart was also considered. This usually results in a communication between the right coronary sinus and the right ventricle. The murmur is usually lower than that of patent ductus arteriosus, and ceases to be continuous when the right ventricular pressure rises. There is usually progressive enlargement of the heart, and the prognosis is bad. The longest reported survival is that of a woman who lived 17 years after the rupture occurred (Morgan Jones and Langley, 1949).

The cardiac catheterization gave a false confirmation of the clinical diagnosis of patent ductus arteriosus.

When the history of the case is examined in conjunction with the operative findings it is reasonable to assume that the continuous murmur was not present when the patient was 21 years of age. This supports the postulate of Lewis (1930) that the presence of a congenital arteriovenous fistula may not become manifest until late in life.

\section{Summary}

A case of congenital arteriovenous fistula of the internal mammary vessels is described.

A diagnosis of patent ductus arteriosus was made despite several unusual features, and was later proved to be incorrect. Thoracotomy was performed at the age of 34 owing to increasing dyspnœa on exertion, although this was possibly due to asthma.

The arteriovenous fistula was removed by quadruple ligation and excision.

We are most grateful to Mr. O. S. Tubbs and to Dr. G. W. Hayward for their permission to pub lish this case.

Adams, H. D. (1951). Surg. Gyn. Obst., 92, 693.

\section{References}

Biorck, G., and Crafoord, G. (1947). Thorax, 2, 65.

Callander, C. L. (1920). Johns Hopk. Hosp. Rep., 19, 259

Edwards, E. A., and Levine, H. D. (1952). New Eng. J. Med., 247, 502.

Elkin, D. C., and Warren, J. V. (1947). J. Amer. med. Ass., 134, 1524.

Halpert, B. (1929). Heart, 15, 129.

Johnson, J. (1954). J. Amer. med. Ass., 155, 1408.

Lewis, D. D. (1930). Lancet, $2,621$.

Maier, H. C., and Stout, A. P. (1950). Circulation, 1, 809.

Morgan Jones, A., and Langley, P. A. (1949). Brit. Heart J., 11, 325.

Paul, O., Sweet, R. H., and White, P. D. (1949). Amer. Heart J., 37, 441.

Pemberton, J. de J., and Saint, J. H. (1928). Surg. Gyn. Obst., 46, 470.

Peräsalo, O., and Kyllönen, K. E. J. (1954). Amer. Heart J., 48, 465.

Salvesen, H. A., and Marstander, F. (1951). Acta. med. Scand., 139, 167.

Takaro, T., and Clagett, O. T. (1951). J. Thoracic Surg., 21, 444.

Wood, P. (1950). Brit. med. J., 2, 639. 